\title{
Odun Kuvars İkameli Plastik Kompozit Malzeme Özelliklerinin Araştırılması
}

\author{
Korkmaz Yıldırım ${ }^{1}$ \\ 1*Aydın Adnan Menderes Üniversitesi, Aydın Meslek Yüksekokulu, İnşaat Teknolojisi Bölümü, 09900 Aydın / TÜRKiYE, ORCID:0000-0002-7470-2297, \\ kyildirim@adu.edu.tr
}

(International Conference on Design, Research and Development (RDCONF) 2021 - 15-18 December 2021)

(DOI: $10.31590 /$ ejosat.1039897)

\begin{abstract}
ATIF/REFERENCE: Yıldırım, K. (2021). Odun Kuvars İkameli Plastik Kompozit Malzeme Özelliklerinin Araştırılması. Avrupa Bilim ve Teknoloji Dergisi, (32), 152-159.

Öz

Doğal kaynakların sınırlı olması nedeniyle giderek azaldığı dünyada, atık malzemelerin geri dönüşüm ile tekrar üretime kazandırılması büyük önem arz etmektedir. Bu çalışma kapsamında Odun-Kuvars takviyeli kompozit malzemelerin mekanik ve termal özellikleri incelenmiştir. Çıkan sonuçlar incelendiğinde, eğilme deneyi sonunda kırılmanın olmaması, numunenin tekrar eski boyutlarına dönmesi malzemenin plastik özelliğinden kaynaklanmaktadır. Çekme, Vida Çekme ve Janka Sertlik Deneyi sonuçlarında, ikame katkı oranlarının farklı olmasından dolayı, önemli derecede direnç değerlerinde değişiklik görülmüştür. Thermogravimetric Analiz deneyi sonuçlarında, üretilen numunenin $470-500{ }^{\circ} \mathrm{C}^{\prime}$ ye ulaştığında tamamen bozulduğu, sadece kuvars kaldığ 1 görülmüştür. DSC sonuçlarında pik noktası $10-15 \mathrm{~m} / \mathrm{W}$ 1sı akış hızında gerçekleşmiş, erime sıcaklığı $110-140^{\circ} \mathrm{C}$ aralığında görülmektedir. SEM sonuçlarında göre komponentlerin karışımları tutarlılık göstermiştir. Sonuç olarak kuvars sertliği etkisini göstermiş, kuvars miktarı arttıkça direnç değerlerinin artmış, kompozit malzeme içerisindeki komponentlerin birbirleri ile uyum sağladığı ve homojen dağıldığ görülmektedir.
\end{abstract}

Anahtar Kelimeler: Kuvars, Ahşap tozu, Kompozit Malzeme, Eğilme, Enjeksiyon

\section{The Investigation of Wood Quartz Replaced Plastic Composite Material Properties}

\begin{abstract}
In a world where natural resources are gradually decreasing due to limited resources, it is of great importance to recycling waste materials into production. In this study, the mechanical and thermal properties of wood-quartz reinforced composite materials were investigated. In terms of the results, it can be repeated from the samples of the bending from the experience to the experience, from the samples to the characteristics of the old products. In the results of Tensile, Screw Tensile, and Janka Hardness Tests, significant changes were observed in the resistance values due to the different ratios of substitution additives. In the results of the Thermogravimetric Analysis experiment, it was observed that the produced sample completely deteriorated when it reached $470-500{ }^{\circ} \mathrm{C}$, and only quartz remained. In the DSC results, the peak point occurred at a heat flow rate of $10-15 \mathrm{~m} / \mathrm{W}$, and the melting temperature was observed in the range of $110-140^{\circ} \mathrm{C}$. According to the SEM results, the mixtures of the components showed consistency. As a result, quartz hardness showed its effect, as the amount of quartz increased, the resistance values increased, it was observed that the components in the composite material were compatible with each other and homogeneously distributed.
\end{abstract}

Keywords: Quartz, Wood powder, Composite Material, Bending, Injection

\footnotetext{
* Sorumlu Yazar: Aydın Adnan Menderes Üniversitesi, Aydın Meslek Yüksekokulu, İnşaat Teknolojisi Bölümü, 09900 Aydın / TÜRKIYE, ORCID:0000-0002-74702297, kyildirim@adu.edu.tr
} 


\section{Giriş}

Dünyamızda her geçen gün yeni malzemelerin üretiminde metal malzemeler kadar dayanıklı, hafif, atmosferik iklim şartlarına direnç gösteren polimer içeren kompozit malzemelerin üretimi ve kullanım alanlarına yönelik çalışmalar yaygınlaşmaktadır.

Polimer içerikli ürünlerin imalatında makine, kalıp yapımı alanlarında görülen teknolojik araştırmalara bakıldığında plastikodun kompozit ürün teknolojileri ülkemiz ve dünyada ham maddeleri hızla azaldığı günümüzde büyük önem arz etmektedir. Beyaz eşya, otomotiv, havacılık, gıda, mobilya ve inşaat sektöründe olmak üzere birçok sektörde üretilen plastikler ile polimer kompozit ürünleri görmekteyiz. Nano partikül içeren dolgulu polimer kompozitler, fiziksel, termal, kimyasal dayanıklıkları ve atmosferik iklime gösterdiği direnç nedeniyle endüstrinin ve araştırmacıların ilgisini çekmektedir. Hammadde eksikliği, çevre kirliliği ve ürün maliyetlerinin artması yenilenebilir hammadde araştırmalarına neden olmaktadır. Odunplastik içerikli kompozit malzemeler, plastiğin dayanımı ve ahşabın dayanımı yönünden ikisinin de en uygun performans ile maliyet fayda-yarar avantajlarını bir arada toplayan kompozit materyali oluşturur. Sağladığı fayda-yarar katkılarından nedeniyle ormancılık ve orman ürünleri sektöründe hizmet veren fabrikalarda atıkların değerlendirilmesi adına odun-plastik kompozit malzeme alanına yöneldiği görülmektedir (Clemons, 2002).

Odun-plastik kompozit malzemeler her geçen gün insan oğlunun yaşam sürecinde yer almaktadır. Genellikle sosyal alanlarda yer alan diş mekan mobilyalarında ve farklı alanlarda kullanım alanı bulmaktadır. Kullanım alanlarında görülen bu artışın sebebi olarak odun-plastik kompozit malzemelerin atmosferik- iklimsel koşullara (rutubet, çürüme, mantar vb.) dayanım göstermesi sayılabilir(Altuntaş, Salan, Alma,2016).

Ahşap plastik kompozit malzeme sektörü atıkların değerlendirilmesinde kullanılan alanlardan biridir. Bu sektör odun kökenli atıklar, çay fabrikası atıkları vb. günümüzde sıklıkla kullanılmaktadır. Ürünleri güçlendirme adına içerisine değişik fiber malzeme veya kalsit gibi mineral malzemeler de değerlendirilmektedir (Günay, Yörür, Şeker, Birinci, 2018).

Odun-plastik kompozit malzemelerin üretiminde kullanılan termoplastik malzeme olarak polipropilen, yüksek ve düşük yoğunluklu polietilen tercih edilmektedir. Polipropilen, yüksek ve düşük yoğunluklu polietilen ürünlerde sağlamlılık, kolay işlenebilirlik, dielektrik özelliği, maliyetinin düşük olması tercih sebebidir. Saf halde bulunan polimerlerden beklenen yukarıda sayılan özellikleri sağlayamayız. Düşük yoğunluklu polietilenleri de dezavantajları nedeniyle kullanımları sınırlıdır. Bu ve buna benzer nedenlerden dolayı kullanılan polimerleri işleyerek bazı özelliklerini değiştirebilmekteyiz. Bu sayede üretilen odunplastik kompozit malzemelerin üretiminde kullanılan polipropilen, yüksek ve düşük yoğunluklu polietilenin mekanik özelliklerinin performansı artmakta olup böylece üretilen kompozit malzemelerin kullanım alanları da genişlemekte olduğu görülmektedir (Yang, Yang, Li, Sun, Feng, 2006).

Odun-plastik kompozit malzemelerin üretiminde kullanılan dolgu malzemeleri olarak kullanılan atık malzemeler (odun tozu, kuvars, mermer tozu vb.) kolay bulunması, üretim maliyetini düşürmekle birlikte, üretim sırasında makinelerde aşınmaya ve üretim ekipmanlarının az zarar görmeleri nedeniyle kullanımları yaygınlaşmıştır. Polipropilen, yüksek yoğunluklu ve düşük yoğunluklu polietilen malzemeler ile üretilen kompozit malzemelerde kullanılan dolgu malzemesi inorganik kalsiyum karbonat (CaCO3)'tır (Hanım, Zarina, Ahmadfuad, Ishak, Hassan, 2008).

Odunsu ve yıllık bitkilerin lifleri ve odunsu ürünlerin unları (tozları) polimer termoplastikler ile bir araya getirildiğinde oluşan bu yeni malzemeye odun plastik kompozit adı verilmektedir. Odun lif veya toz oranının \%50'den fazla olması gerekir. Odun plastiklerin özelliklerini kullanılan odun/lif yapısı, termoplastik polimerin molekül ağırlığı, katkı maddesi ve uyum sağlayıcı maddeler oluşturur (Mengeloğlu, 2006). Odun plastik kompozitlerde odun malzemeler veya sıkılaşmış Mdf, sunta gibi yan ürünlerin tozları olabilir. Odun unu olarak ahşap tozları kompozit malzemenin sertliğini artırırken dayanıklılı̆̆ını azaltır (Jeong, 2005). Odun plastik kompozit malzeme üretiminde termoplastik reçineler (Polietilen, Polipropilen) ve odun tozları kullanılmaktadır. Kompozit malzeme üretiminde ucuzluk, düşük yoğunluk, yüksek mukavemet, aşınmanın az olması, doğada bozunabilir olması lignoselülozik esaslı liflerin kullanılmasını cazip kılmaktadır (Chen, 2009).

İlk odun plastik kompozit odun unu ve fenoliklerin karıştırılmasıyla 1907 yılında üretilmiş, ticari kullanım olarak 1916 yılında araçlarda vites kolu olarak üretilip kullanılmıştır. 1997 yılında \% 2 olan pazar payı, 2005 yılında \%18'e çıkarak odun plastik kompozit üretiminde ciddi artış gözlenmiştir. Artık dünyanın birçok bölgesinde bu ürünlerin üreticisi bulunmaktadır (Mengeloğlu, 2006;Rowel, 2006;10- Balma,1999).

Bu çalışma içeriğinde termoplastik malzeme, odun tozu (unu) ve kuvars mineralini belirli miktarlarda extrüde ederek, 100 bar basınç ve 45 sn enjeksiyon yüklemesi yapılarak kalıplama yöntemiyle deney numuneleri üretilmiş, üretilen kuvars ikameli odun plastik kompozit malzeme deney numuneleri mekanik deneylerle araștırılmış, ürün olarak kullanılabilirliği, orijinal hammaddelerin hızla tükenmekte olduğu dünyamızda atık malzemelerin geri dönüşüm yoluyla ekonomiye kazandırılması amaçlanmıştır.

\section{Deneysel Çalışma Materyal ve Metot}

\subsection{Deneysel Çalışmada Kullanılan Malzemeler}

\subsubsection{Mineral Agrega Kuvars}

Dolgu malzemesi olarak kuvars, sertliğinin yüksek olması nedeniyle yapımında kullanıldı̆̆ yüksek mukavemet kazandırdığı için tercih edilmektedir. Çalışma kapsamında kullanılan kuvars agregasına ait kimyasal ve fiziksel teknik özellikler tablo 1 'de gösterilmiştir.

\subsubsection{Petilen G03-5 (Alçak Yoğunluklu Petilen) (AYPE)}

Servis ömrünün uzunluğu, üretilen ürünlerin dayanıklılığı, uyumu, her türlü dış etkilere gösterdiği dayanıklılık nedeniyle plastiklerin kullanım alanı olarak boru üretimi ilk sıradadır.

Her türlü pissu ve temiz su tesisatlarında kullanılan boru imalatında Alçak Yoğunluklu Petilen (AYPE) 1950 yılından beri yaygın kullanılmaktadır (Maria, Rode, ShusterVd. 2015).

Günümüzde plastik atıkların yaklaşık \%42'sini alçak yoğunluklu petilen oluşturmaktadır. İnsanoğlunun yaşamında plastik ürünlerde bozunmayı önleyen katkıların kullanılarak ürünlerin servis ömrünü arttırmaya amaçlayan çalışmalar hız kazanmıştır. 
Plastiklerde ürün işleme, depolama, kullanımı sonrasında geri dönüşüm süreçlerinde görülen radikal süreçlerde gerçekleşen bozunmayı sağlayan tepkimeler kullanılan polimerin yapısal içeriğini değiştirdiği görülmüştür (Cruz, Zanın, 2003).

Yüksek basınç otoklav prosesi ile geniş molekül ağırlığı dağılımında üretilmiş, düşük erime akış hızına sahip ürün alçak yoğunluklu polietilen olup PETİLEN G03-5 sembolü ile piyasada bulunmaktadir (ASTM-D618-96, 1998).
Enjeksiyonla kalıplama uygulamalarında ideal bir malzemedir. Uygulanmasında Enjeksiyonla kalıplama metodu kullanılır. Tavsiye edilen işleme koşulları 160-220 ${ }^{\circ} \mathrm{C}$ aralığında olup kullanılan petilen G03-5 ürünü teknik özellikleri tablo 1 'de verilmiştir.

Tablo 1. Termoplastik (AYPE) ve Kuvars Mineraline ait Teknik Özellikler

\begin{tabular}{|c|c|c|c|c|}
\hline \multirow[b]{2}{*}{ Reçine Özellikleri } & \multicolumn{2}{|c|}{ PETÍLEN (AYPE) G03-5 } & \multicolumn{2}{|c|}{$\begin{array}{l}\text { KUVARS MINERALI } \\
\text { ÖZELLIKLERİ }\end{array}$} \\
\hline & $\begin{array}{l}\text { Tipik } \\
\text { Değer }\end{array}$ & Birim & Ürün boyutu & 0-75 mikron \\
\hline $\begin{array}{l}\text { Erime Akış hızı (230 } \\
\left.{ }^{\circ} \mathrm{C}\right)\end{array}$ & 0,30 & $\mathrm{~g} / 10 \mathrm{~min}$ & Sertlik derecesi & 7 mohs \\
\hline $\begin{array}{l}\text { Yoğunluk } \\
\text { Ergime Noktasl (DSC) }\end{array}$ & $\begin{array}{c}0,920 \\
110\end{array}$ & $\begin{array}{c}\mathrm{g} / \mathrm{cm}^{3} \\
\mathrm{oC}\end{array}$ & Özgül ağırlık & $2,65 \mathrm{gr} / \mathrm{cm}^{3}$ \\
\hline \multicolumn{2}{|c|}{ Mekanik Ö̈zellikler } & & \multicolumn{2}{|c|}{ Kuvars Kimyasal Analiz Raporu } \\
\hline $\begin{array}{l}\text { Akmada Gerilme } \\
\text { Dayanımı }\end{array}$ & 12 & $\mathrm{MPa}$ & Bileşik & Bileşik A $\breve{g} ı r l ı \breve{g} 1$ \% \\
\hline $\begin{array}{l}\text { Kopmada Gerilme } \\
\text { Dayanımı }\end{array}$ & 26 & MPa & $\mathrm{SiO}_{2}$ & 97.13 \\
\hline Kopmada Uzama (MY) & $>250$ & $\%$ & $\mathrm{Al}_{2} \mathrm{O}_{3}$ & 1.72 \\
\hline Bükülme Modülü, 23 oC & ----- & $\mathrm{MPa}$ & $\mathrm{Fe}_{2} \mathrm{O}_{3}$ & 0.029 \\
\hline $\begin{array}{l}\text { İzod Darbe Dayanımı } \\
23 \text { oC }\end{array}$ & ----- & $\mathrm{J} / \mathrm{m}$ & $\mathrm{TiO} 2$ & 0.031 \\
\hline Sertlik (Shore-D) & ----- & R-scale & $\mathrm{CaO}$ & 0.06 \\
\hline Rockwell Sertliği & ---- & R-scale & $\mathrm{MgO}$ & 0.02 \\
\hline $\begin{array}{l}\text { Çevresel baskıyla } \\
\text { kırılma dayanımı }\end{array}$ & ----- & saat & $\mathrm{Na}_{2} \mathrm{O}$ & 0.91 \\
\hline \multicolumn{3}{|c|}{ Termal Özellikler } & $\mathrm{P}_{2} \mathrm{O}_{5}$ & 0.00 \\
\hline $\begin{array}{l}\text { Deformasyon Sicaklığı } \\
0,45 \mathrm{Mpa}\end{array}$ & 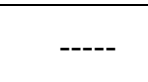 & ${ }^{\circ} \mathrm{C}$ & & \\
\hline $\begin{array}{l}\text { Vicat Yumuşama } \\
\text { Noktas1, 10N }\end{array}$ & 98 & ${ }^{\circ} \mathrm{C}$ & & \\
\hline
\end{tabular}

\subsubsection{Ahşap Tozu}

Çalışma kapsamında mobilya sektöründe atık malzeme olarak geri kalan ahşap ve ahşap ürünlerine ait makine artığı tozlar kullanılmıştır. Tozların karışım oranları sabit olmayıp; çam, kayın, kavak, mdf, sunta, ahşap artığı ve bazı kenar bantlarına ait talaş ve tozlar toplanmıştır. $\mathrm{Bu}$ atık malzeme $105{ }^{\circ} \mathrm{C}$ etüvde kurutulduktan daha sonra ögütülmüş ve 200 mesh incelikte olan elekten elenerek odun unu şeklinde toz malzeme üretilmiştir (Horta, Simoes, Mateus, 2017). Bu karışım içerisinde bulunan maddelerin analiz değerlerine bakıldığında selüloz maddesinin çokluğu görülmektedir. Deneysel çalışmada kullanılan ahşap tozuna (unu) ait özellikler tablo2'de verilmiştir.

Tablo 2. Ahşap Tozu (unu) Teknik Özellikleri

\begin{tabular}{|c|c|c|}
\hline Elementsel Analiz & Ăğırlıkça Analiz & Kimyasal analiz \\
\hline $\begin{array}{c}\mathrm{C} \\
50,02 \\
\end{array}$ & $\begin{array}{c}\text { \% Uçucu Madde } \\
75,68\end{array}$ & $\begin{array}{l}\text { \% Özütlenebilir madde } \\
\qquad, 8\end{array}$ \\
\hline $\begin{array}{c}\mathrm{H} \\
6,62\end{array}$ & $\begin{array}{c}\% \text { Kül } \\
1,01\end{array}$ & $\begin{array}{c}\text { Hemi } \\
\text { selüloz } \\
11,1\end{array}$ \\
\hline $\begin{array}{c}\mathrm{N} \\
1,96 \\
\end{array}$ & $\begin{array}{c}\% \mathrm{Nem} \\
4,10 \\
\end{array}$ & $\begin{array}{c}\text { \% Selüloz* } \\
56,1\end{array}$ \\
\hline $\begin{array}{l}S \\
-\end{array}$ & $\begin{array}{c}\text { \% Sabit } \\
19.21\end{array}$ & $\begin{array}{c}\text { \% Lignin } \\
23,0\end{array}$ \\
\hline $\begin{array}{c}* \\
47,66 \\
\end{array}$ & $\begin{array}{c}\text { C Isıl Değer (cal/g )* } \\
5413,9\end{array}$ & 9,8 \\
\hline
\end{tabular}




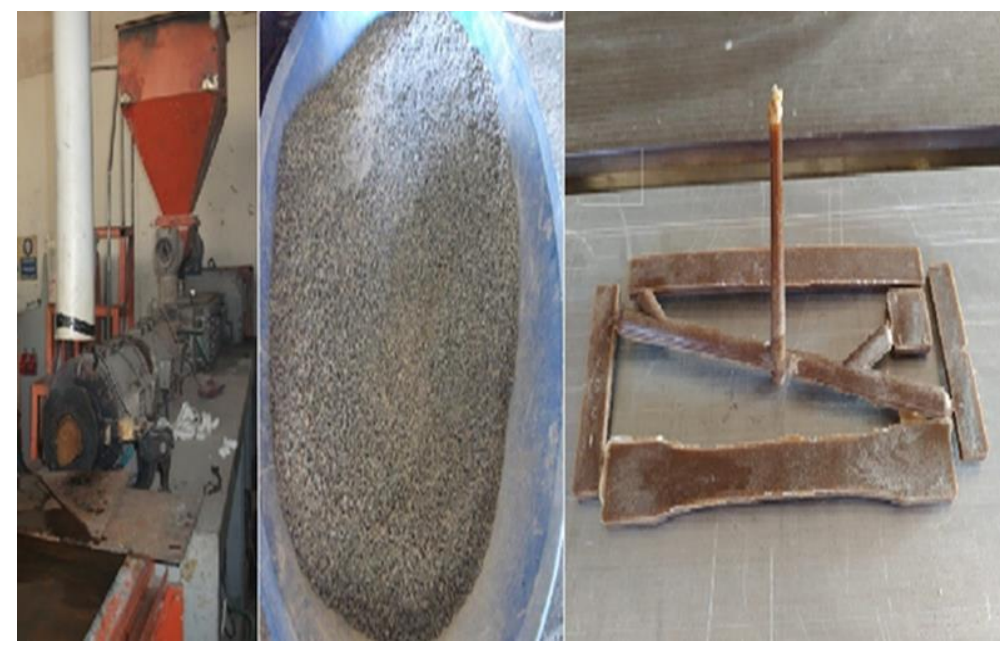

Şekil 1. Malzeme Karışımlarının Extrüder - Kırma Ve Enjeksiyon Makinasında Üretilen Deney Numuneleri Aşamaları

Tablo 3. Deney Numune Gruplarının Karışım Oranları

OPK-K1 - Kuvars - Ahşap Tozu - Alçak Yoğunluklu

Petilen Plastik

OPK-K2 - Kuvars - Ahşap Tozu - Alçak Yoğunluklu

Petilen Plastik

OPK-K2 - Kuvars - Ahşap Tozu - Alçak Yoğunluklu

Petilen Plastik

\subsection{Deney Numuneleri Hazırlığı}

Termoplastiklerden Alçak Yoğunluklu Petilen malzeme (AYPE), sanayi artığı olan 200 mesh incelikte ahşap tozu (unu) ve $0,100 \mu$ (mikron) altı incelikte kuvars minerali belirli oranlarda yer değiştirme metodu ile hazırlanmıştır. Odun, Plastik,

Kuvars kompozit malzemesi için hazırlanan deney gruplarına ait isimlendirme ve karışım oranları tablo 3 'de verilmiştir.

Bu çalışmada, termoplastik malzeme, odun ve kuvars ile ayrı ayrı hazırlanan malzemeler mikserde karıştırılmış, dolgu malzemesi olarak kuvars, odun tozu ve alçak yoğunluklu petilen (PE) kompozitler çift vidalı ekstrüder kullanılarak üretilmiştir (Şekil.1).

Polimer içerikli kompozit malzeme üretiminin gelişmesinde ekstrüzyon işlemi önemli role sahiptir. Extrüder makinasında yapılan ekstrüzyon işleminde makine içinde bulunan silindirik bir kovan ve içinde dönen vida sayesinde polimer işleme tekniği gelişmiştir. Kompozit malzeme üretiminde kullanılan polimerlerin \%60'1 bu makinede işlenerek karışım tamamlanan son ürün haline gelir (Bodur, 2010).

Extrüder makinasında bir araya getirilen numuneler granül hale getirildi. Enjeksiyon makinası için granül hale gelen malzeme etüvde belirli sicaklıkta bekletilerek rutubet ve nemden arındırma işlemi gerçekleştirilmiş. Hazırlanan malzeme ile mekanik ve termal deneyleri yapacağımız deney numunelerin oluşumu için enjeksiyon makinasında 100 bar basınç ve 45 sn enjeksiyon yüklemesi yapılarak kalıplama yöntemiyle deney numuneleri üretilmiştir (Şekil.1). Her üç grup malzeme aynı üretim aşamalarından geçerek kompozit malzeme üretilmiştir.

\section{Deneysel Süreç ve Sonuçları}

Kuvars, 200 mesh inceliğinde ahşap unu (tozu), termoplastik ürün (alçak yoğunluklu petilen) belirli karışımlarda yer değiștirme usulü ile hazırlanmış, hazırlanan malzeme ile extrüder ve enjeksiyon işlemleri sonrasında testlerde kullanılan deney çubukları üretilmiştir. Deney numunelerine standartlar kapsamında eğilme, çekme, vida çekmeve janka sertlik deneyleri uygulanmış deneylere ait sonuçlar ve grafikleri aşağıda yorumlanmıştır (ASTM-D790ISO178,2007; TS EN 323, 1999). (Şekil 2). Alçak Yoğunluklu Petilen ait deney çubuklarında eğilme, çekme, vida çekme ve janka sertlik deneylerinde, maksimum kuvvet karşısında aldığı deney sonuç değerleri tablo 4'de ve deney sonuç değerlerine ait grafik şekil 3'de görülmektedir.

\subsection{Eğilme Deneyi}

Eğilme Deneyinde; K-0 referans numunenin aldığı eğilme mukavemeti $10,85 \mathrm{~N} / \mathrm{mm}^{2}$ seviyesinde çıkmış, OPK-K1 nolu numunede; referans numuneye göre maksimum kuvvet ve eğilme mukavemetinde \% 34 seviyesinde artışın olduğu, OPK-K2 nolu numunede referans numuneye göre eğilme direncinde $\% 38$ seviyesinde artışın devam ettiği, OPK-K3 nolu numunede odun tozunun az, kuvars mineralinin fazla olduğunda; referans numuneye göre maksimum kuvvette ve eğilme mukavemetinde \% 33 seviyesinde artışın olduğu, OPK-K2 nolu numune grubuna göre \%7,8 seviyesinde azalma gözlenmiştir. Kuvarsın fazla olduğu OPK-K3 nolu numunede maksimum kuvvet ile eğilme mukavemeti göreceli olarak düşüş göstermiştir.

\section{2. Çekme Deneyi}

Alçak yoğunluklu polietilen referans numunede; K-0 referans numunenin aldığı çekme mukavemeti $9,32 \mathrm{~N} / \mathrm{mm}^{2}$ seviyesinde çıkmış, OPK-K1 nolu numunede; referans numuneye çekme mukavemetinde \% 23,6 seviyesinde azalmanın olduğu, OPK-K2 
nolu numunede; OPK-K1 nolu numune grubuna göre, çekme direncinde \% 12,1 seviyesinde artışın olduğu, OPK-K3 nolu numunede; referans numuneye göre çekme mukavemetinde $\% 11$ seviyesinde bir azalama, OPK-K2 nolu numuneye göre maksimum kuvveti ve çekme mukavemetinde \% 2,4 seviyesinde artışın olduğu gözlenmiştir.

\subsection{Vida Çekme Deneyi}

Alçak yoğunluklu polietilen referans numunede; K-0 referans numunenin aldığı vida çekme mukavemeti $44 \mathrm{~N} / \mathrm{mm}^{2}$ dolayında çıkmış, OPK-K1 nolu numunede; referans numuneye göre, vida çekme mukavemetinde \%1,09 seviyesinde azalma olduğu, OPKK2 nolu numunede; referans numuneye göre, vida çekme mukavemetinde \%13 seviyesinde artışın olduğu, OPK-K3 nolu numunede; OPK-K2 nolu numuneye göre vida çekme mukavemetinde \%1 seviyesinde artışın olduğu buna göre vida çekme mukavemetinin kuvars katkısı ile uyumlu arttığı,

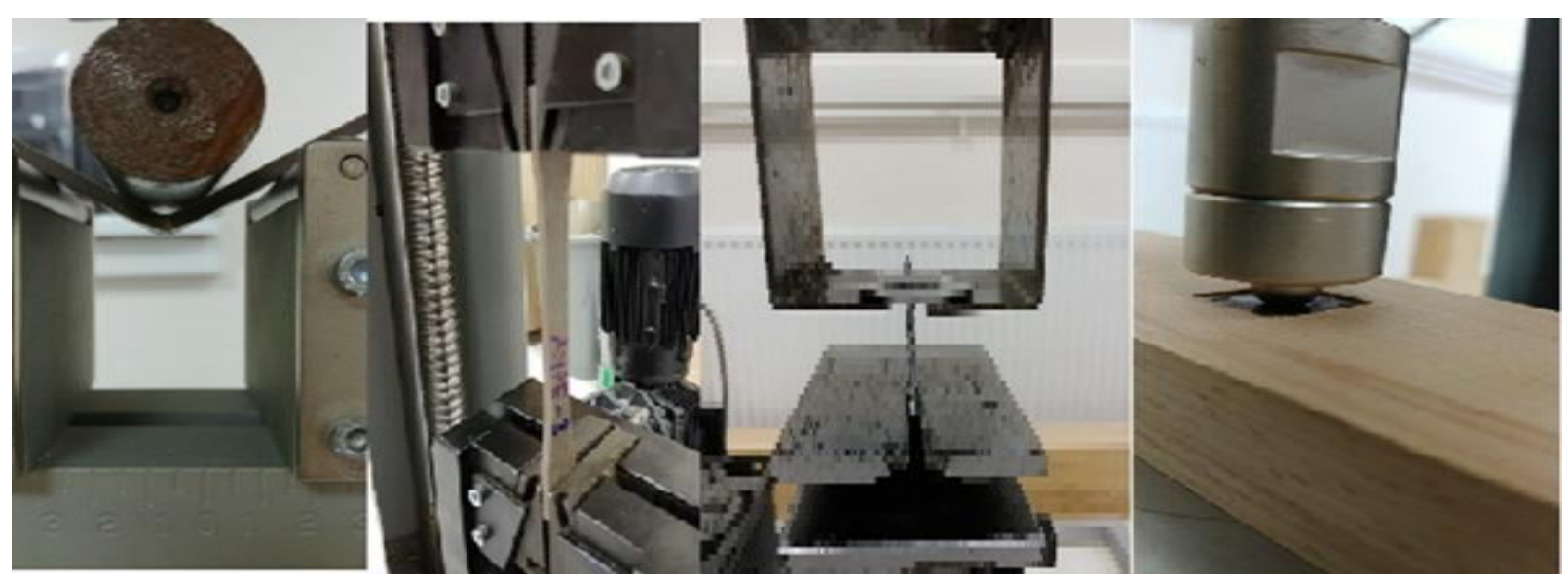

Şekil 2. Deney Numunelerine Uygulanan Eğilme, Çekme, Vida Çekme ve Janka Sertlik Deney Süreçlerine Ait Görüntüleri

Tablo 4. Düşük Yoğunluklu Petilen Numunelere Yapılan Eğilme, Çekme, Vida Çekme Ve Janka Sertlik Deney Sonuçları

\begin{tabular}{|c|c|c|c|c|}
\hline & Eğilme Direnci & Çekme direnci & Vida Çekme direnci & Janka sertlik direnci \\
\hline Referans $K-0$ & 10.8487 & 9.3163 & 44.6203 & 16.99825 \\
\hline$O P K-K 1$ & 16.5489 & 7.0984 & 44.1300 & 16.6844 \\
\hline$O P K-K 2$ & 17.6522 & 8.0905 & 50.9947 & 18.9595 \\
\hline$O P K-K 3$ & 16.2731 & 8.2948 & 51.4850 & 17.4428 \\
\hline
\end{tabular}

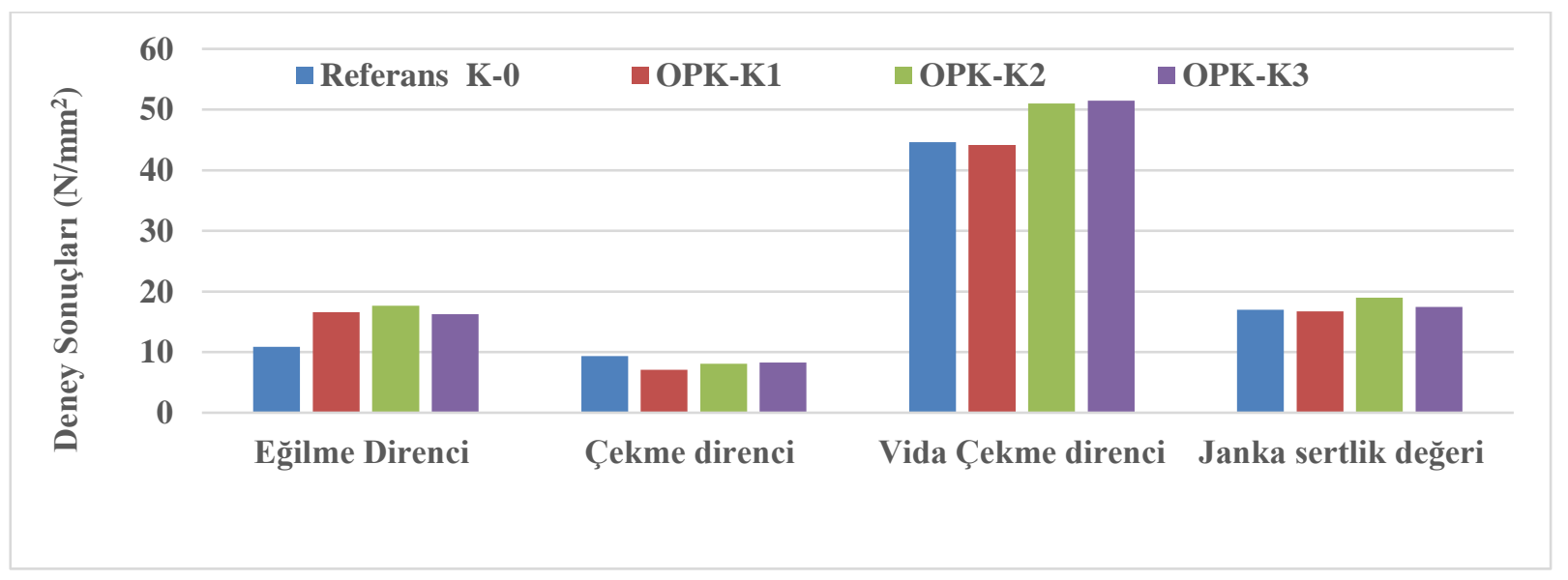

Şekil 3. Alçak Yoğunluklu Petilen Numunelere Yapılan Ĕ̆ilme, Çekme, Vida Çekme Ve Janka Sertlik Deney Sonuçları Grafiği 


\subsection{Janka Sertlik Direnci Deneyi}

Alçak yoğunluklu Petilen referans numunede; K-0 referans numunenin aldığı janka sertlik değeri $16,99 \mathrm{~N} / \mathrm{mm}^{2}$ dolayında çıkmış, OPK-K1 nolu numunede; referans numuneye göre, maksimum kuvveti ve janka sertlik değerinde \%1,8 seviyesinde azalmanın olduğu, OPK-K2 nolu numunede; referans numuneye göre, janka sertlik değerinde \%10 seviyesinde artışın olduğu; OPK-K3 nolu numune grubunda, OPK-K2 nolu gruba göre, janka sertlik değerinde $\% 8$ seviyesinde azalmanın olduğu, OPK-K3 nolu numunede; OPK-K1 nolu numuneye göre, çekme direncinde $\%$ 4,3 seviyesinde artışın olduğu buna göre janka sertlik değerinin $\operatorname{arttığ1}$,

\subsection{Thermogravimetric Analiz (TGA)}

Deneysel çalışmada üretilen kompozit numunelere 1sıtma hızı $30^{\circ} \mathrm{C} / \mathrm{dk}$., azot akış hızı $20 \mathrm{ml} / \mathrm{dk}$. seçilerek $700{ }^{\circ} \mathrm{C}$ 'ye kadar 1sıya karşı davranışı ölçülen Thermogravimetric Analysis TGA analizi gerçekleştirilmiştir.

Elde edilen sonuçlara göre içerisinde katkı bulunmayan Alçak Yoğunluklu Petilen numuneler yaklaşık $470^{\circ}$ civarında tamamen bozunmuş ve ağırlığını kaybetmiştir.

İçerisinde ahşap tozu ve kuvars bulunan numunelerde plastik malzemenin bozunması $300{ }^{\circ} \mathrm{C}$ derece civarında başlamış, 470 $500{ }^{\circ} \mathrm{C}$ 'ye varıncaya kadar polietilen malzeme ile ahşap tozunun yok olduğu geriye sadece kuvarsın kaldığı görülmüştür. Kuvarsın yanma sıcaklığının yüksek olması nedeniyle, $500{ }^{\circ} \mathrm{C}$ 'den sonra kuvarsın bozunmadan ağırlığını koruduğu gözlenmiştir.

Mineral olarak kuvarsın kompozit malzemedeki bozunmay geciktirdiği, aynı zamanda bozunma sıcaklıklarını uzattığı anlaşılmıştır.

\subsection{Diferansiyel Taramalı Kalorimetre (DSC) analizi}

Diferansiyel Taramalı Kalorimetre Polimer filmlerin cams geçiş sicaklıkları(Tg), Perkin Elmer Diamond Diferansiyel Taramalı Kalorimetre (DSC) cihazı kullanılarak azot atmosferinde ve $20{ }^{\circ} \mathrm{C} / \mathrm{dk}$. tarama hızıyla gerçekleştirildi. Analizden önce numuneler $45{ }^{\circ} \mathrm{C}$ 'de vakum altında 1 gün bekletildi. Analiz iki aşamada gerçekleştirildi. İlk aşamada numuneler $20{ }^{\circ} \mathrm{C}^{\prime}$ den $100{ }^{\circ} \mathrm{C}$ 'e isitılarak ön 1sitma işlemi gerçekleştirildi. İkinci aşamada ise numuneler $-20{ }^{\circ} \mathrm{C}$ 'e soğutularak ve bu sıcaklıktan $250{ }^{\circ} \mathrm{C}^{\prime}$ ye kadar isıtıldı.

Şekil 5'deki Alçak yoğunluklu polietilen, ahşap tozu ve kuvars katkılı numuneler üzerinde yapılan DSC analiz grafiğine göre, deney numunelerinin reaksiyona başlama sıcaklığı $30^{\circ} \mathrm{C}$ civarındadır.
Alçak yoğunluklu Petilenin pik noktası katkılı olanlara göre 19 m/W ısı akış hızında iken, ahşap tozu ve kuvars katkılı olan gruplarda ise $10-15 \mathrm{~m} / \mathrm{W}$ 1sı akış hızında gerçekleşmiştir. Tüm gruplarda ise erime sıcaklığı $110-140^{\circ} \mathrm{C}$ aralığında gözlenmiştir.

\subsection{Alçak Yoğunluklu Petilen, Ahşap Tozu ve Kuvars İkameli Kompozit Elemanlarda Scanning Electron Mikroskopu (SEM) Analizi}

Şekil 6'da Scanning Electron Mikroskopu (SEM) Görüntülerinde deney numunelerinin içine katılan ahşap tozu ve kuvarsın polimerik kompozit eleman içerisinde homojen olarak dağılım göstermiştir. Karışıma giren komponentlerin içeride segmentlerle uyumlu olduğu ve aralarındaki bağlanma açıça görülmüştür

\section{Sonuçlar}

Kuvars ikameli odun plastik kompozit malzemede eğilme direnci, çekme, vida çekme ve janka sertlik deneyi genel sonuçları aşağıdaki çıkmıştır.

Eğilme deneyi sonunda kırılmanın olmaması, eğilme deneyi başladığında numuneler maksimum kuvvete kadar direnç göstermiş olup, eğilme sonucunda numunenin tekrar eski boyutlarına dönmesi malzemenin plastik özelliğini göstermiştir Karışıma giren malzemelerin birbiri ile uyumu sayesinde numunelerde kırılma ve çatlak oluşmamıştır.

Çekme deneyine tabii tutulan numunelerde enjeksiyon sırasında makine hızına bağlı olduğu düşünülen deney numunesinin bazı kısımlarında boşluklar kaldığı bu nedenle çekme direncinin düşük çıktığı gözlendi. Boşlukların oluşmaması için enjeksiyon makine hızı ayarına dikkat edilmesi gerekmektedir.

Janka sertlik direnci deneyi sonuçları ve Vida çekme deneyi sonuçlarında alçak yoğunluklu polietilen numunelerde vida çekme direncinde artış görülmüştür. Bunun sebebi olarak polietilenin teknik özelliğinden kaynaklandığı söylenebilir. Vida çekme deneyi numunelerinde kuvarsın sertliği etkisini göstermiştir. Kuvars miktarı arttıkça vida çekme direnci de artmıştır. Üretilmesi düşünülen malzeme açısından karışımların uyumlu olması mekanik özellikler açısından olumlu sonuçları getirmiştir.

Janka sertlik deneyi numunelerinde kuvarsın sertlik etkisinin görüldüğü, kuvars miktarının arttığında janka sertlik direnci değerinde arttığı gözlenmiştir. 


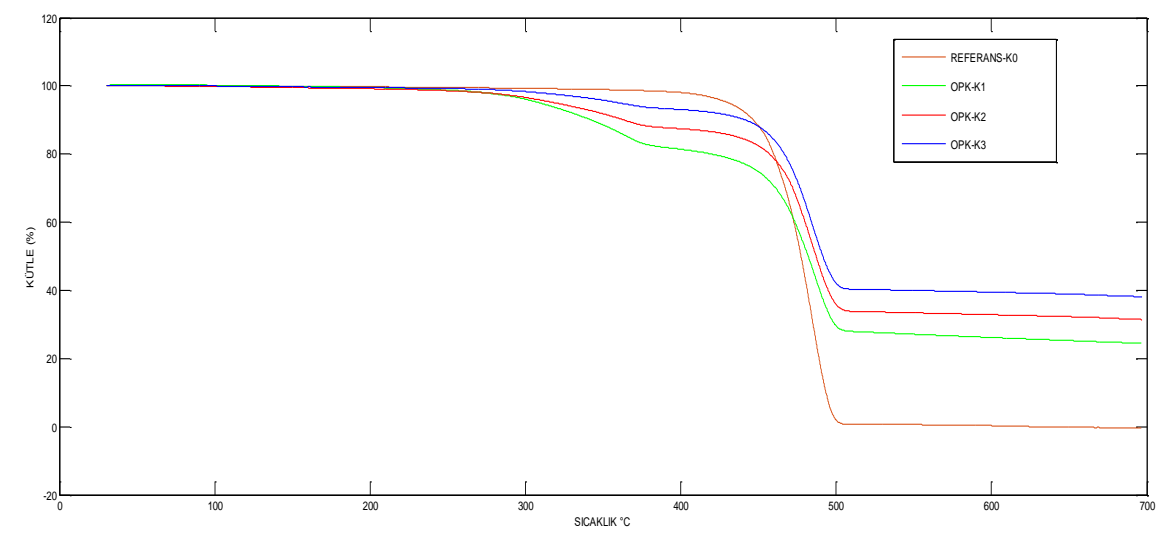

Şekil 4. Alçak Yoğunluklu Petilen Numunelerde Thermogravimetric Analiz Deney Sonuçları Grafiği

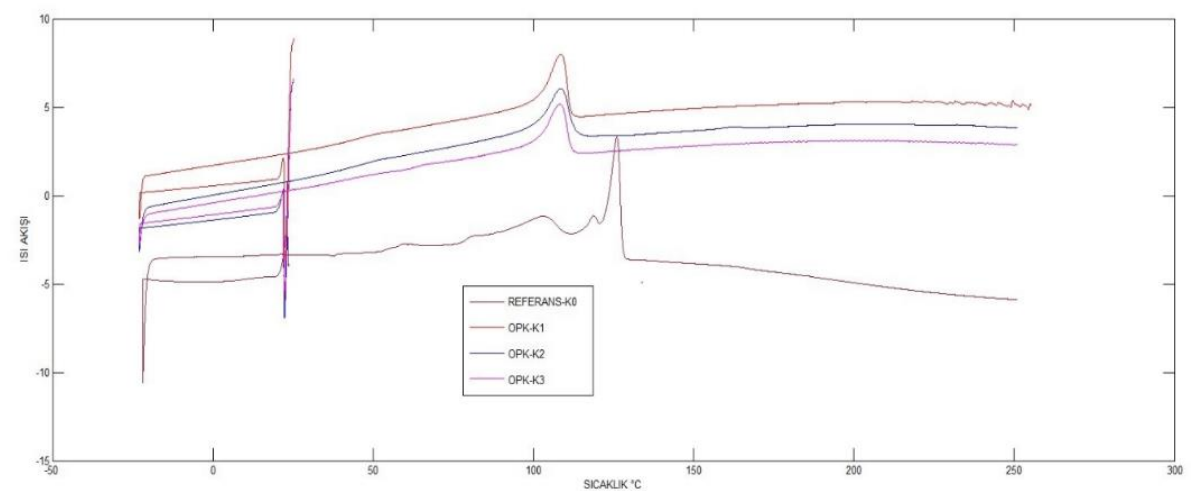

Şekil 5. Alçak Yoğunluklu Petilen Numunelerde Diferansiyel Taramalı Kalorimetre Deney Sonuçları Grafiği

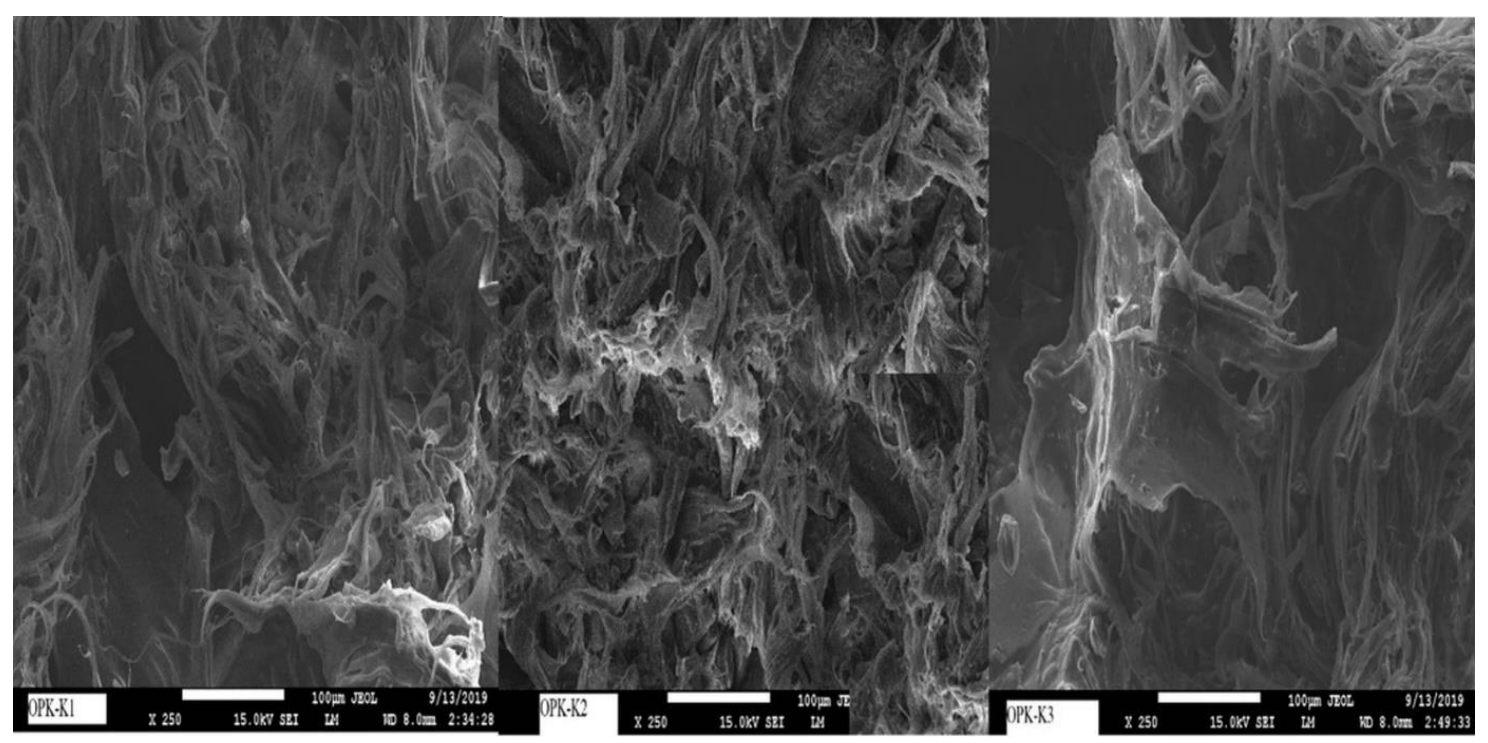

Şekil 6. Alçak Yoğunluklu Petilen Numunelerde Scanning Electron Mikroskopu (Sem) Görüntüleri

Termoplastik katk1lı gruplarda kuvars ikamesi fazla olan numunelerde göreceli olarak artı̧̧ gösterdiği, plastik katkının teknik özelliği nedeniyle alçak yoğunluklu polietilen malzemenin referans numunelerinde ortaya çıkan sonuçlara göre karışım içinde bulunan kuvars ve odun tozunun uyumlu çalıştı̆̆ söylenebilir.
Kompozit numunelere uygulanan Thermogravimetric Analysis (TGA) deney sonuçlarına göre plastik ve odun esaslı malzeme $470-500{ }^{\circ} \mathrm{C}$ 'ye ulaştığında tamamen bozunmuş, geriye sadece kuvars minerali kalmıştır.

Diferansiyel Taramalı Kalorimetre (DSC) deneyinde katkılı numunelerde pik noktası 10-15 $\mathrm{m} / \mathrm{W}$ 1sı akış hızında gerçekleşmiş, erime sıcaklığ $110-140^{\circ} \mathrm{C}$ aralığında gözlenmiştir. 
Scanning Electron Microscope (SEM) numune analiz sonuçlarına göre karışım içerisine giren komponentlerin karışımda homojen dağılım ve tutarlılık göstermiştir.

Çalışmamızda plastik alçak yoğunluklu petilen (AYPE), odun tozu ve kuvars minerali ikameli deney numuneleri üzerinde yapılan deney sonuçlarına göre plastik kompozit üretiminde kuvarsın kullanılabilirliği gözlenmiş olup, deneyler sonucunda kuvars ile odun tozu ve alçak yoğunluklu petilenin eğilme mukavemeti, çekme mukavemeti, vida çekme ve janka sertlik mukavemetlerinde artış sağlanmıştır. Kuvarsın fazla kullanıldığg kompozitlerde en büyük mukavemet değerlerine ulaşılmıştır.

Deney sonuçlarına göre alçak yoğunluklu petilen, kuvars ve odun tozu ile oluşan kompozit malzeme içerisindeki komponentlerin birbirleri ile uyum sağladığı ve homojen dağılım gösterdiği görülmüştür.

\section{Kaynaklar}

Clemons C, (2002), "Wood-plastic composites in the United States - The interfacing of two industries", Forest Products Journal, 52, 10-8.

Altuntaş, E., Salan, T., Alma, HM., (2016), "Farklı Bor Bileşik Kullanılarak MDF-AYPE Odun Plastik Kompozitlerin Yangına Dayanıklılı̆̆ının Araştırılması", KSU Mühendislik Bilimleri Dergisi, 19(3), 19-23.

Günay, NM., Yörür, H., Şeker, B., Birinci, E., (2018), "The Effects on The Mechanical Properties of The Composite Material Obtained from Waste Fiber", 1 st International Symposium on Light Alloys and Composite Materials (ISLAC'18) Karabük, 495-499.

Yang, J., Yang, Q., Li, G., Sun, Y., Feng, D., (2006), "Morphology and mechanical properties of polypropylene/calcium carbonate nanocomposites", Materials Letters, 60, 805-809.

Hanim, H., Zarina R., Ahmad Fuad, MY., Ishak, ZA. and Hassan A., (2008), "The Effect of Calcium Carbonate Nanofiller on the Mechanical Properties and Crystallisation Behaviour of Polypropylene", Malaysian Polymer Journal, 3, 38-51.

Mengeloğlu,F., (2006), "Wood-Thermoplastic Composites", 1. Polimerik Kompozitler Sempozyumu ve Sergisi, TBMOB Kimya Mühendisleri Odası, İzmir, 471-480.

Jeong, G., (2005), " Fracture Behavior of Wood-Plastic Composites (WPC) ", LSU Master's Thesis B.S., Chonnam National University,

Chen,L., (2009), " Extrudable MelamineResin for Wood Plastic Composite, Master of Science Civil Engineering", Washington State Untversity/ Department of Civil and Environmental Engineering, 8-9.

Rowel, Roger M., (2006), "Advances and Challenges Wood Polymer Composites", Proasceeding of the 8th Pacific RimBio- Based Composites Symposium, 1-10.

Balma, A., (1999), "Evaluation of Bolted Connections in Wood Plastic Composites, Master of Science Civil Engineering", Master's Thesis, Washington State Unıversity/ Department of Civil and Environmental Engineering, 86.

Maria, R., Rode, K., Schuster, T., vd., (2015), "Ageing study of different types of longterm pressure tested PE pipes by IRmicroscopy", Polymer, 61, 131-139.

Cruz , S.A., Zanin M., (2003), "Evaluation and identification of degradative processes in post-consumer recycled highdensity polyethylene", Polym. Degrad. Stab., 80, 31-37.

ASTM-D618-96, (1998), "Standard Practice Forconditioning Plastic Fortesting", American Society for Testing and Materials, Philadelphia, ASTM.
Horta, FJ., Simões, FJ., Mateus, A., (2017), "Study of WoodPlastic Composites with reused High Density Polyethylene and Wood Sawdust" Procedia Manufacturing , 1.12, 221-229.

Bodur, M.S., (2010), "Geri Dönüşüm İşleminin Tekstil Atığ 1 Takviyeli Polimer Matrisli Karma Malzemelerin Mekanik Özellikleri Üzerine Etkisi", İstanbul Teknik Üniversitesi, Fen Bilimleri Enstitüsü, Yüksek Lisans Tezi, İstanbul, 83.

ASTM D 790 ISO 178, (2007), "Standard test methods for flexural properties of unreinforced and reinforced plastics and electrical insulating materials", Annual Book of ASTM Standards, West Conshohocken, PA, Vol. 08, 01,

ASTM D 638-99 ISO 527-1, (2007), "Standard test methods for tensile properties of plastics", Annual Book of ASTM Standards, West Conshohocken, PA, USA, 08-01.

ASTM D1037, (2020), "Standard Test Methods for Evaluating Properties of Wood-Base Fiber and Particle Panel Materials", Annual Book of ASTM Standards, USA..

TS EN 323, (1999),"Ahşap Esaslı Levhalar-Birim Hacim Ağırlığının Tayini", TSE Standardı, Ankara.

TS EN 326, (1999),"Ahşap Esaslı Levhalarda Numune alınması ve Deney Parçalarının Hazırlanması", TSE Standardı, Ankara. 